\title{
Efficient Planar Perovskite Solar Cells with Reduced Hysteresis and Enhanced Open Circuit Voltage by Using $\mathrm{PW}_{12}-\mathrm{TiO}_{2}$ as Electron Transport Layer
}

Chun Huang ${ }^{1}$, Canjun $\mathrm{Liu}^{2}$, Yunxiang $\mathrm{Di}^{1}$, Wenzhang $\mathrm{Li}^{2}$, Fangyang $\mathrm{Liu}^{1,3 *}$, Liangxing Jiang $^{1}, \mathrm{Jie} \mathrm{Li}^{1,2}$, Xiaojing $\mathrm{Hao}^{3}$, Haitao Huang ${ }^{4 *}$

1 School of Metallurgy and Environment, Central South University, Changsha 410083, China

2.College of Chemistry and Chemical Engineering, Central South University, Changsha 410083, China

3 School of Photovoltaic and Renewable Energy Engineering, University of New South Wales, Sydney,

NSW 2052, Australia

4 Department of Applied Physics, The Hong Kong Polytechnic University, Kowloon , Hong Kong, China

\section{${ }^{*}$ Corresponding Author}

E-mail addresses: liufangyang@csu.edu.cn (Fangyang, Liu), haitao.huang@polyu.edu.hk (Haitao, Huang) 

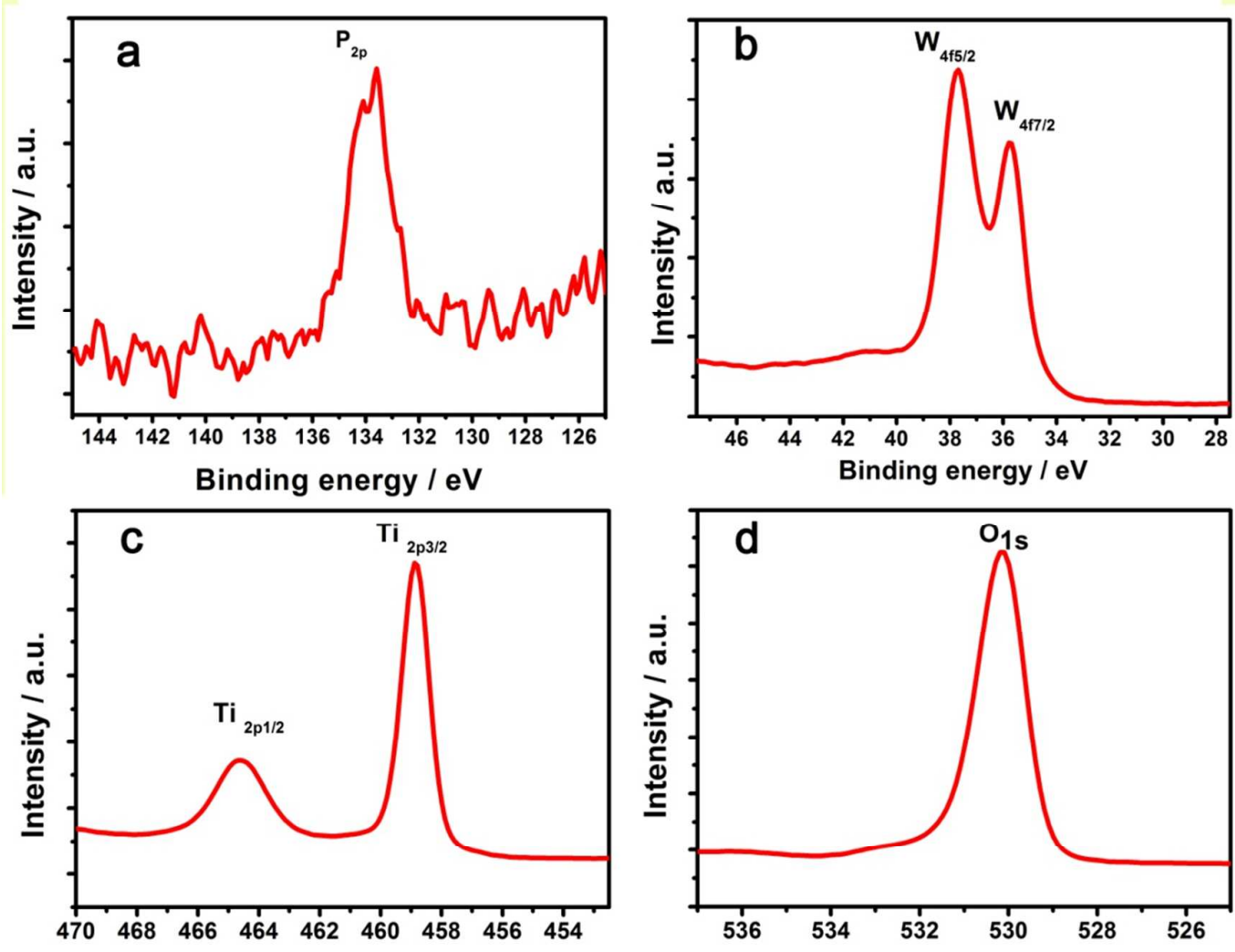

Fig. S1. XPS spectra for $\mathrm{P}, \mathrm{W}, \mathrm{Ti}$, and $\mathrm{O}$ elements in $\mathrm{PW}_{12}-\mathrm{TiO}_{2}$ films.
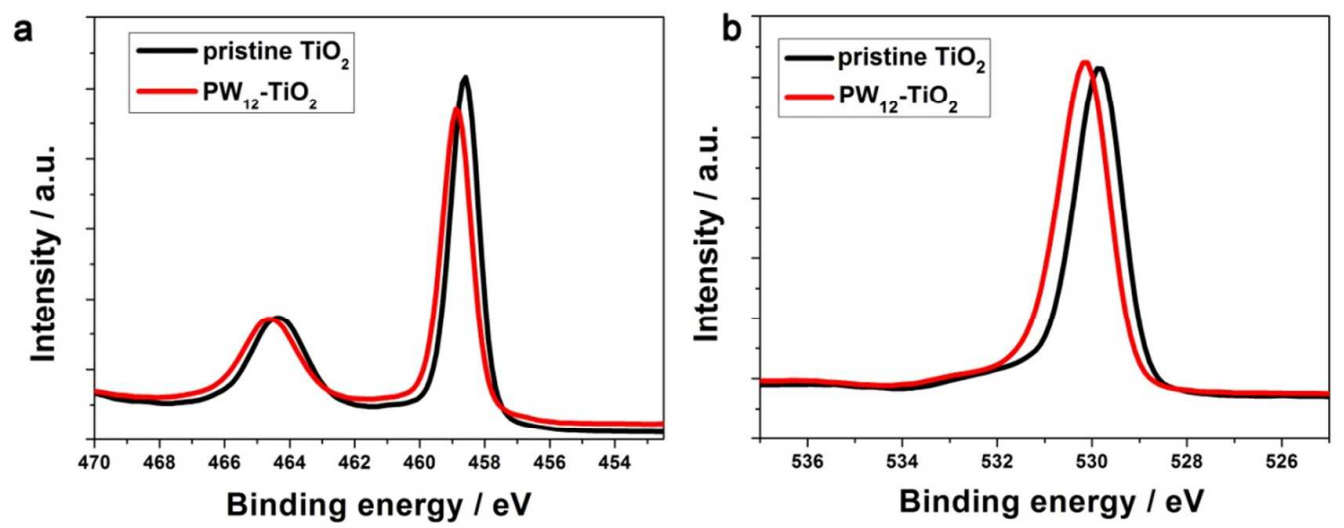

Fig. S2. Ti and O XPS spectra of $\mathrm{PW}_{12}-\mathrm{TiO}_{2}$ and pristine $\mathrm{TiO}_{2}$, demonstrating the change of chemical environment for $\mathrm{TiO}_{2}$ in $\mathrm{PW}_{12}-\mathrm{TiO}_{2}$ film 

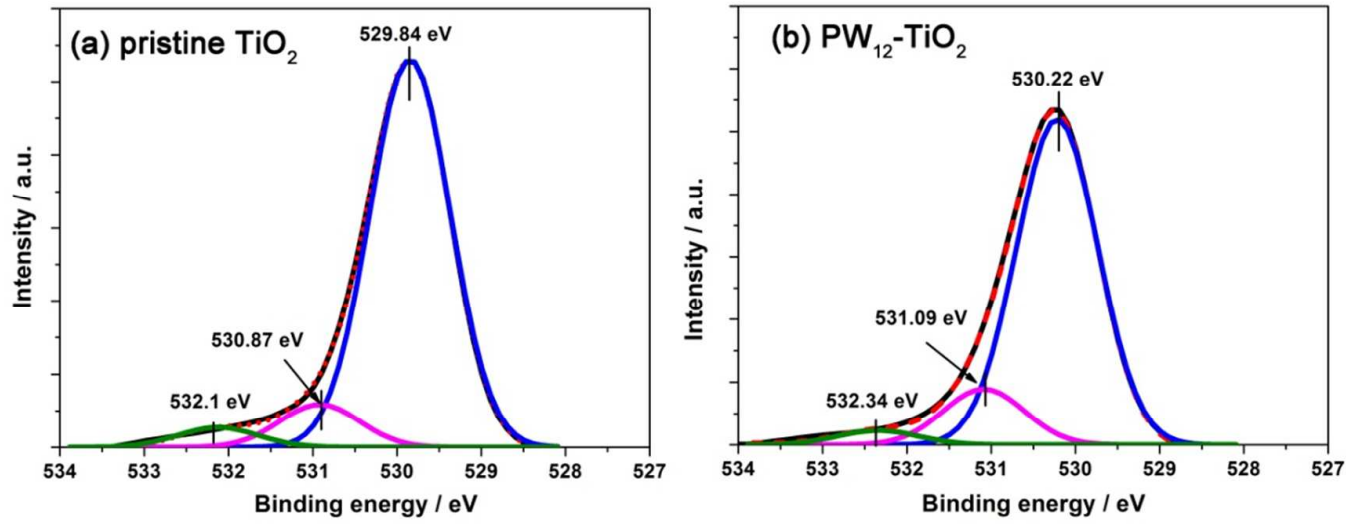

Fig. S3. Fitting of O1s XPS spectra of (a)pristine $\mathrm{TiO}_{2}$ and (b) $\mathrm{PW}_{12}-\mathrm{TiO}_{2}$. In both case, the $\mathrm{O} 1 \mathrm{~s}$ peaks can be deconvoluted to three O1s peaks. For pristine TiO2, peak located at 529.84 $\mathrm{eV}$ could be ascribed to $\mathrm{O}$ in $\mathrm{TiO}_{2}$, while $530.87 \mathrm{eV}$ and $531.10 \mathrm{eV}$ could be assigned to surface adsorbed hydroxyls, hydrocarbonates and carbobates. For $\mathrm{PW}_{12}-\mathrm{TiO}_{2}$, peak at 530.22 $\mathrm{eV}$ could be assigned to $\mathrm{O}$ in $\mathrm{TiO}_{2}$, and $530.09 \mathrm{eV}$, and $532.55 \mathrm{eV}$ could be assigned to surface adsorbed hydroxyls, hydrocarbonates and carbobates.

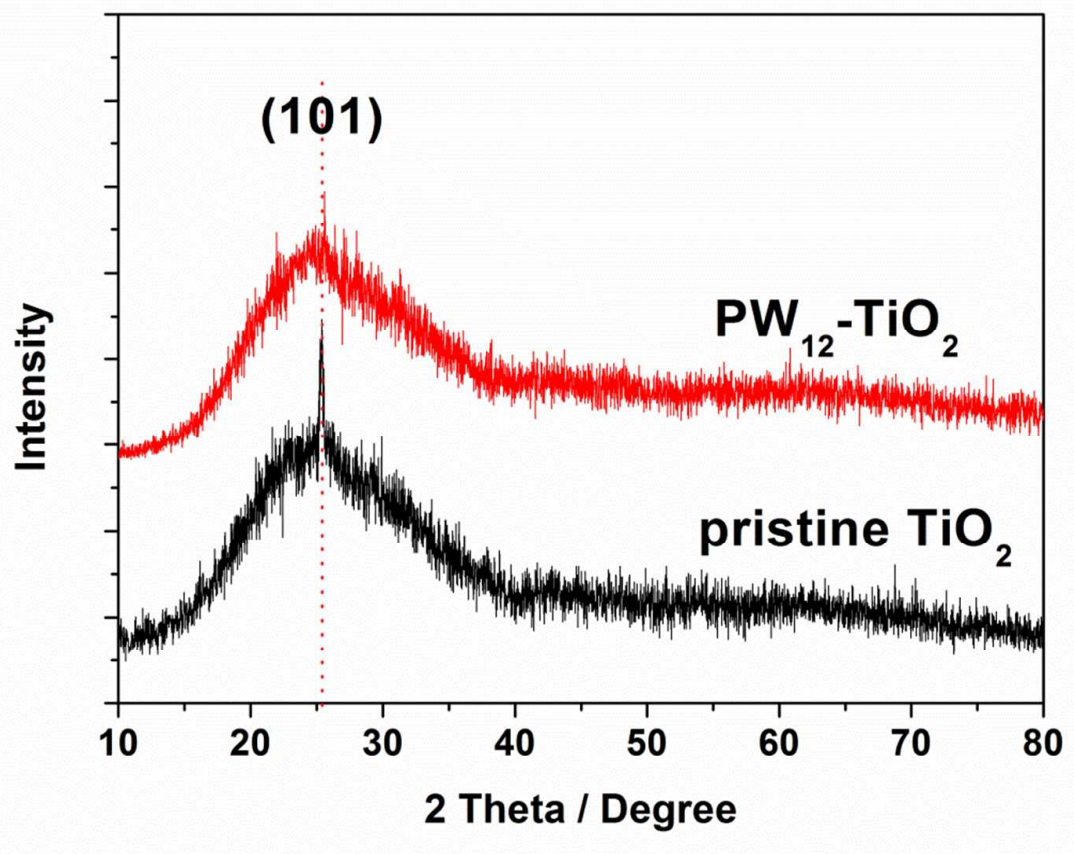

Fig. S4. XRD patterns for pristine $\mathrm{TiO}_{2}$ and $\mathrm{PW}_{12}-\mathrm{TiO}_{2}$ thin films. The samples were prepared by repeating the spin coating 4 times. The preferred growth of (101) direction was not observed in $\mathrm{PW}_{12}-\mathrm{TiO}_{2}$, agreeing with previous reports and indicating the doping of W6+ in anatase $\mathrm{TiO}_{2}$. 

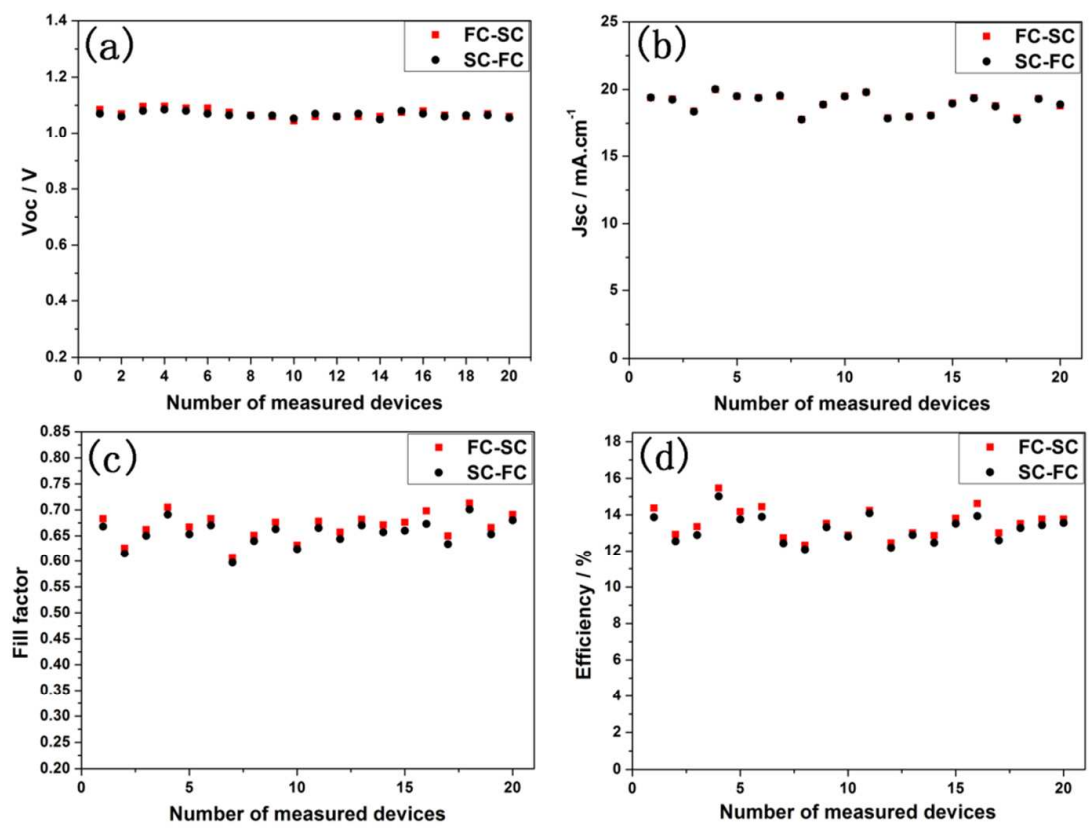

Fig. S5. Statics about Voc (a), Jsc (b), FF (c), and efficiencies (d) for 20 measured $\mathrm{PW}_{12^{-}}$ $\mathrm{TiO}_{2}$-based devices.

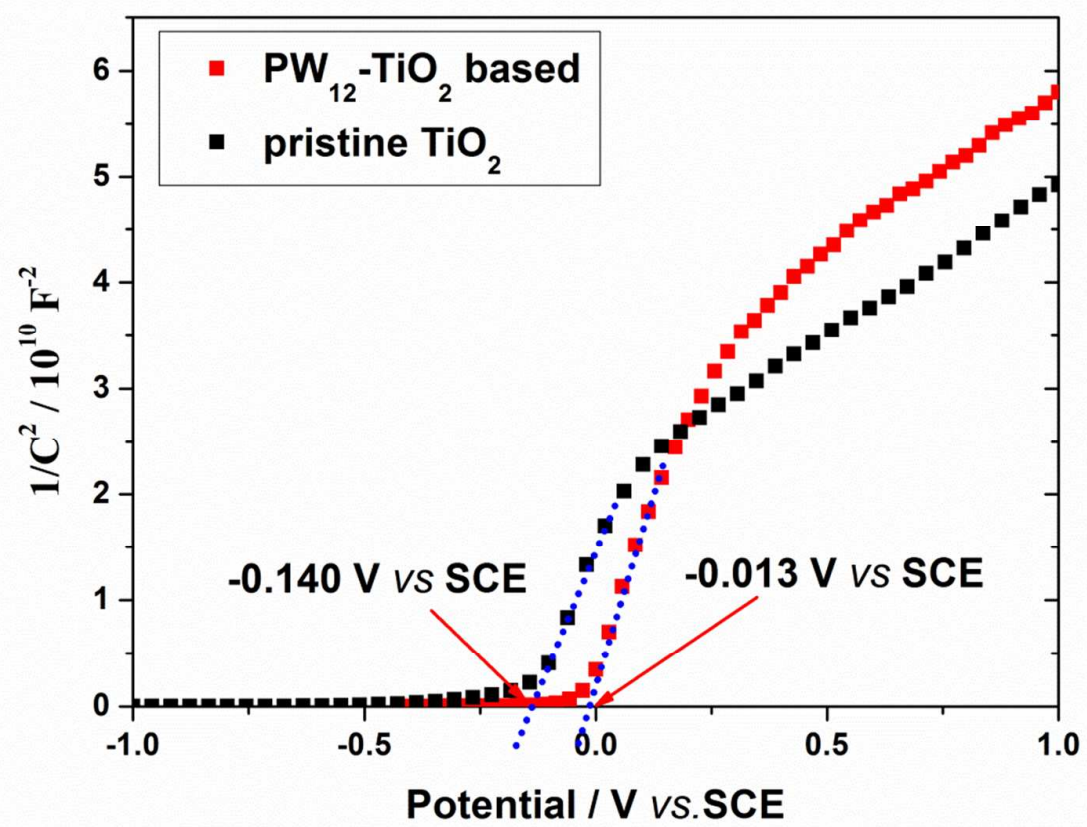

Fig. S6. Mott-Schottky plot of $\mathrm{PW}_{12}-\mathrm{TiO}_{2}$ and pristine $\mathrm{TiO}_{2}$ films in $\mathrm{Na}_{2} \mathrm{SO}_{4}$ solution $(0,1 \mathrm{M})$ 


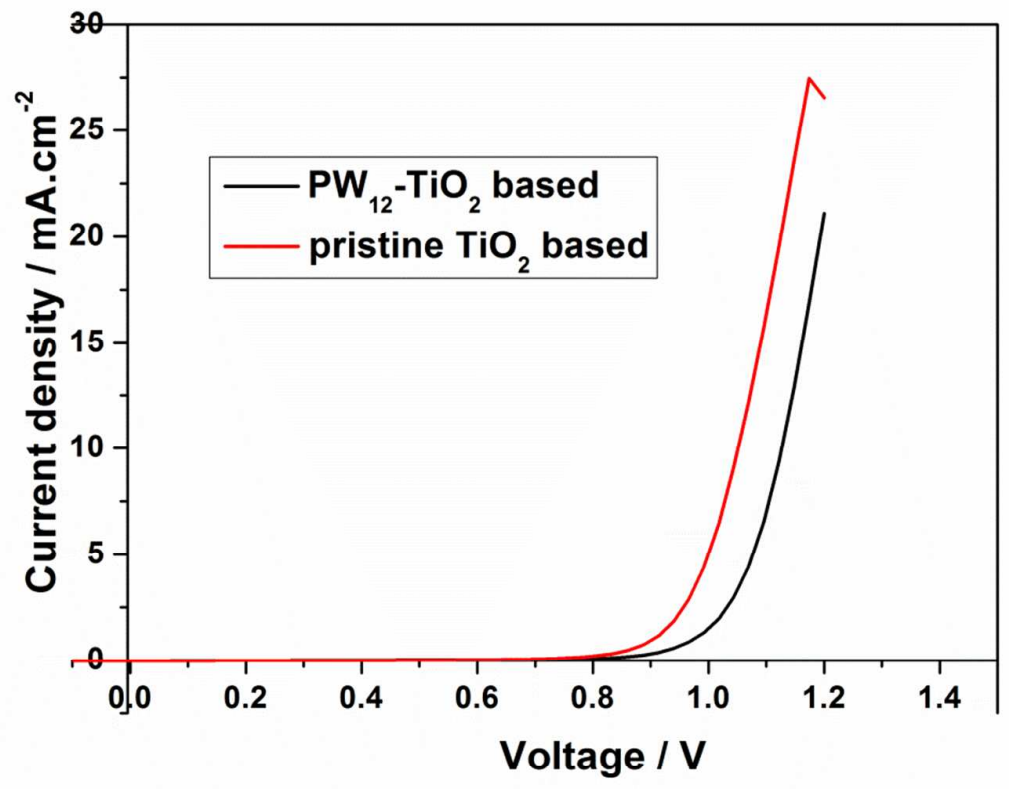

Fig. S7. The J-V curves showing the dark current of perovskite solar cells based on $\mathrm{PW}_{12^{-}}$ $\mathrm{TiO}_{2}$ or $\mathrm{TiO}_{2}$ ETL (indicative of recombination). 